\title{
Ekonomik Göstergelere Dayalı Tedarikçi Seçimi için Sezgisel Bulanık Yaklaşım
}

\author{
Ayşenur AKIN VARGELOĞLU1 $\quad$ Mükerrem Bahar BAŞKIR ${ }^{2} \quad$ Hamza GAMGAM $^{3}$
}

Geliş Tarihi (Received): 31.03.2021- Kabul Tarihi (Accepted): 27.09.2021

\section{Öz}

Artan rekabet ortamında varlığını sürdürmek isteyen işletmeler için tedarikçi seçim ve değerlendirmeleri önemli bir yere sahiptir. İşletmeler uygun tedarikçi seçimi ile müşteri beklentilerini en iyi şekilde karşılamayı hedeflemektedir. Bu çalışmada, tedarikçi seçimi ve değerlendirmeleri için sezgisel bulanık kümelere dayalı bütünleşik bir yaklaşım önerilmektedir. Önerilen yaklaşım ile karar verici algı farklılıkları kaynaklı belirsizlikler ait olma ve ait olmama dereceleri ile detaylı şekilde incelenmektedir. $\mathrm{Bu}$ yaklaşım, inşaat sektöründe faaliyet gösteren bir işletmenin tedarikçi seçimi ve değerlendirmelerine uygulanmıştır. Uygulamada, ekonomik kriterlere dayalı karar verici öznel değerlendirmeleri ile işletme mevcut değerlendirme puanları birleştirilerek karma veritabanı oluşturulmuştur. Klasik ve bulanık öbekleme yaklaşımları ile tedarikçi firma sıralama ve sınıflandırmaları elde edilmiştir. Karma veritabanı için bulanık öbekleme yapısı $\% 99,1$; klasik öbekleme yapısı ise $\% 94,4$ doğruluk oranı ile oluşmuştur. Ayrıca, bulanık ve klasik öbekleme sonuçları içerisinde sadece tedarikçi değerlendirme puanlarına ait öbeklemenin, sırasıyla, \%90,7 ve \%74,1 doğruluk oranına sahip olduğu görülmüştür. Alg1 farklılıklarının tedarikçi seçimine yönelik karar almadaki etkileri önerilen bütünleşik yaklaşımla açıklanmıştır.

Anahtar Sözcükler: Sezgisel bulanık küme, tedarikçi seçimi, belirsizlik, bulanık öbek ortalamaları, kortalamalar

\section{Intuitionistic Fuzzy Approach for Supplier Selection Based on Economic Indicators}

\begin{abstract}
Supplier selection and evaluation is an important issue for organizations to cope with increasing competitive environment. Companies aim to meet customer expectations with selection of appropriate supplier. In this study, an integrated approach based on intuitionistic fuzzy sets is proposed for supplier selection and evaluation. In the proposed approach, uncertainties arising from discrepancies in decisionmakers' perception are examined in detail with belonging and non-belonging degrees. This approach was applied to supplier selection and evaluations of a construction company. In practice, a mixed database was created by combining the subjective evaluations of decision makers based on economic criteria and current evaluation scores of the company. Supplies were sorted and classified using the classical and fuzzy clustering approaches. For the mixed database, fuzzy and classical clustering structures were created with $99.1 \%$ and $94.4 \%$ accuracy rates, respectively. Besides, within the fuzzy and classical clustering-results, classification-accuracy rates of only supplier evaluation scores were found as $90.7 \%$ and $74.1 \%$, respectively. The effects of perception discrepancies on decision making for supplier selection were explained by means of the proposed integrated approach.
\end{abstract}

Keywords: Intuitionistic fuzzy set, supplier selection, uncertainty, fuzzy c-means, k-mean

\footnotetext{
${ }^{1}$ Arş. Gör., Gazi Üniversitesi, Fen Fakültesi, İstatistik Bölümü, aysenurakin@gazi.edu.tr; ORCID: 0000-0002-3949-025X

${ }^{2}$ Dr. Öğr. Üyesi., Bartın Üniversitesi, Fen Fakültesi, Matematik Bölümü, mbaskir@ bartin.edu.tr; ORCID: 00000002-1107-0659

${ }^{3}$ Prof. Dr., Gazi Üniversitesi, Fen Fakültesi, İstatistik Bölümü, gamgam@ gazi.edu.tr; ORCID: 0000-0002-9595-9315
} 


\section{Giriş}

Teknolojik gelişmeler ile birlikte işletmeler için küresel rekabet koşullarına ayak uydurma çalışmaları hız kazanmıştır. Öncelikli hedef kaliteli ürün/hizmet ortaya koyarak hızla artan talebi karşılamak ve müşteri memnuniyetini artırmaktır. Bu kapsamda, işletmeler için başarılı bir tedarik zinciri yönetimi ortamdaki rekabet avantajlarını sürdürmelerinde önemli rol oynamaktadır (Öztürk ve Türksoy, 2020). Tedarik zinciri yönetiminin önemli aşamalarından biri uygun tedarikçi seçimi ve değerlendirmeleridir. İşletmelerde mevcut tedarikçiler veya yeni tedarikçiler arasından en uygun olanın seçimi önemli bir unsurdur. Literatürde tedarikçi seçimi konusundaki öncü çalışma Dickson tarafından 1966 yılında gerçekleşmiştir. Dickson’ın çalışmasında 23 kriter içerisinden önem derecesine göre kalite, teslimat, garanti politikası, esneklik vb. olmak üzere 20 esas kriter belirlenmiştir (Dickson, 1966). Tedarikçi seçim süreci, çeşitli kriterler bakımından uygun tedarikçileri seçen çok özellikli karar verme problemidir (Guo ve Li, 2014). Tedarikçi seçim problemlerinde veri yapısı veya karar verici algı farklılıkları kaynaklı belirsizlikler ile karşılaşılmaktadır (Başkır, 2011; 2017). Bu durumda klasik yöntemler ile gerçekleştirilen tedarikçi seçim süreçleri için etkin sonuçlar elde edilemeyebilir. Belirsizlik içeren tedarikçi seçim problemlerinde bulanık küme teorisine dayalı yöntemlerin kullanımı yaygındır. Bulanık küme teorisi ile insan yargısı temeline dayalı belirsizlikler ait olma dereceleri kullanılarak incelenmektedir (Zadeh, 1965). Kavram ve algı farklılığını içeren öznel değerlendirmelerde, algılamalar bulanık ve ölçümler ise kesindir (Zadeh, 2002; Başkır, 2017). Öte yandan, bulanık küme teorisinden geliştirilmiş sezgisel bulanık kümeler, belirsizlikleri ait olma ve ait olmama dereceleri ile daha kapsamlı ele almaktadır (Atanassov, 1999). Bu çalışmada, tedarikçi seçim süreci için sezgisel bulanık kümelere dayalı bütünleşik bir yaklaşım önerilmektedir. Önerilen sezgisel bulanık yaklaşım üç aşamadan oluşmaktadır: i) tedarikçi seçim kriterlerinin belirlenmesi ve değerlendirilmesi, ii) karar verici öznel ve nesnel sezgisel bulanık değerlendirmeleri, iii) durulaştırma sonrası oluşturulan karma veritabanı ile öbekleme (kümeleme) analizi. Karma veritabanı öznel ve nesnel değerlendirmeleri içermektedir. Sezgisel bulanık kümelere dayalı öznel değerlendirmeler ve puanlama temelli değerlendirme sistemi için öbekleme (kümeleme) algoritmalarını içeren yapısı ile bu bütünleşik yaklaşım kullanılarak etkin bir tedarikçi seçim sürecinin sağlanması hedeflenmiştir.

Çalışmanın diğer bölümleri şu şekilde düzenlenmiştir: Birinci bölümde, sezgisel bulanık kümelere dayalı yöntemlerle tedarikçi seçimine yönelik literatür taraması aktarılmaktadır. İkinci bölümde, bu çalışmada önerilen yaklaşım araçları tanıtılmaktadır. Üçüncü bölümde, önerilen sezgisel bulanık yaklaşım adımları açıklanmaktadır. Ayrıca, bu bölümde, önerilen 
yaklaşımda sezgisel bulanık kümelere dayalı değerlendirmelerin uygulaması sayısal örnek ile verilmektedir. Dördüncü bölümde, önerilen sezgisel bulanık yaklaşım gerçek yaşam problemi olarak bir inşaat firmasının tedarikçi seçim sürecine uygulanmaktadır. Beşinci bölümde, yapılan çalışmanın sonuçları aktarılmaktadır.

\section{Literatür Taraması}

$\mathrm{Bu}$ çalışmada önerilen yaklaşımın teorik altyapısının ve uygulama alanının oluşturulmasında yol gösterici olan literatürdeki başlıca çalışmalar aşağıda özetlenmektedir:

Szmidt ve Kacprzyk (2001), sezgisel bulanık kümeleri kullanarak tıbbi teşhis belirsizliklerini incelemede yeni bir yaklaşım önermişlerdir. Her hastanın muhtemel tıbbi teşhis ile uzaklıkları hesaplanmış ve önerilen yaklaşım max-min-max kuralına dayanan De Biswas ve Roy’un yaklaşımı ile karşılaştırılmıştır. Sonuç olarak, yeni yaklaşım ile daha doğru tıbbi teşhis konulduğu tespit edilmiştir.

Liu ve Wang (2007), çok kriterli karar verme problemi için sezgisel bulanık kümeleri kullanarak skor fonksiyonu tanımlamışlardır. Bu fonksiyon ile alternatif tercihlerin karar verici isteklerini sağlayıp sağlamadığı incelenmiştir. Sezgisel bulanık operatör kullanılarak problemlerdeki belirsizlikler incelenmiş ve alternatif tercihler sıralanmıştır.

Mendoza vd. (2008), potansiyel tedarikçi firmaları belirli bir sayıya indirgemek, tedarikçileri sıralamak ve tedarikçi seçimini kolaylaştırmak için bütünleşik AHP-GP yaklaşımını önermişlerdir. Bu yaklaşımı bir üretim tesisinden alınan verilere üç aşamada uygulamışlardır. Çok sayıdaki tedarikçi firma belirli düzeye indirgenmiş, beş kriter için tedarikçiler sıralanmış ve tedarikçilere atanacak en uygun sipariş miktarı bulunmuştur. $\mathrm{Bu}$ çalışma ile çok kriterli tedarikçi seçim problemlerine yeni bir bakış açısı sunulmuştur.

Boran (2009), çok kriterli grup karar verme problemleri için sezgisel bulanık kümeler ile birleştirilen TOPSIS metodunu kullanarak uygun tedarikçinin seçilmesini önermişlerdir. Otomotiv şirketinde yapılan uygulamada üç adet karar verici dört kriter için beş alternatif tedarikçiyi değerlendirmiştir. Karar vericiler ve kriterlerin önemi dilsel değişkenlerle belirtilmiştir. Sezgisel Bulanık Ağırlıklandırma Operatörünü (IFWA) kullanarak kriterler ve alternatiflerin önem dereceleri belirlenmiştir. Sezgisel bulanık pozitif-ideal ve negatif-ideal çözümler hesaplanmıştır. Sezgisel bulanık kümeler ile birleştirilen TOPSIS yöntemi, karar vericilerin belirsizlik algılarını içerdiği için çok kriterli karar verme problemlerinde büyük fayda sağlamıştır. 
Guo vd. (2010), tedarikçi seçim problemi için sezgisel bulanık TOPSIS metodunu kullanmışlardır. Yapılan sayısal örnek ile önerilen yaklaşımın etkili olduğu görülmüştür.

Ho vd. (2010), 2000-2008 yılları arasında uluslararası dergilerde yer alan tedarikçi seçimi için çok kriterli karar verme yaklaşımları ile ilgili makaleleri incelemişlerdir. En yaygın kullanılan yaklaşım Veri Zarflama Analizi (VZA), en popüler bütünleşik yaklaşım ise AHP-GP (Analitik Hiyerarşi Prosesi-Hedef Programlama) bulunmuştur. Tedarikçi seçim probleminde kullanılan en yaygın kriterler kalite, teslimat ve fiyat olarak belirlenmiştir. Çalışma sonucunda çok kriterli karar verme yaklaşımlarının tek kriteri maliyet olan yaklaşımlara göre daha avantajlı olduğu bulunmuştur.

Boran (2011), tesis lokasyonunun seçilmesi için TOPSIS metodunu sezgisel bulanık ortama genişleterek çok kriterli bir karar verme yöntemi önermiştir. Bir imalat şirketinin lokasyon seçimi için sezgisel bulanık TOPSIS metodu kullanılmıştır. Önerilen yöntemin önemli karar alma problemlerinde genişletilebileceği belirtilmiştir.

Kaur (2014a), üçgensel sezgisel sayıları kullanarak çok amaçlı bir optimizasyon problemi ile tedarikçi seçim problemine yeni bir yaklaşım önermiştir. Tedarikçi seçim probleminde IFMOLM (Intuitionistic Fuzzy Multiobjective Linear Model) kullanılmıştır. Bu çalışmada özgün olarak LPP (Liner Programming Problem) sezgisel bulanık formda ifade edilmiştir. Sayısal bir örnek ile sezgisel yaklaşımla elde edilen sonuçların bulanık yaklaşıma göre daha iyi olduğu görülmüştür.

Kaur (2014b), üçgensel sezgisel bulanık sayıları (TIFN) kullanarak, tedarikçi seçim probleminde Analitik Hiyerarşi Prosesinine (AHP) dayalı bir yaklaşım önermiştir. TIFN-AHP metodolojisini geliştirmek için teknoloji şirketinde sayısal bir örnekle adımları göstermiştir. Araştırmada beş kriter kullanılarak duyarlılık analizi yapılmıştır. Duyarlılık analizi sonucunda tedarikçi seçiminde etkili kriterler belirlenmiştir.

Sotirova vd. (2014), sezgisel bulanık kümelere dayalı değerlendirmeler ile doktora adaylarının çeşitli kriterlere göre puanlarını hesaplamışlardır. SOM algoritması kullanılarak adaylar altı kümeye ayrılmıştır. Önerilen yaklaşım ile doktora adaylarının seçimi ve ilerlemesi gözlenmiştir.

Kaur ve Pal (2015), tedarikçi seçimi problemine dilsel değişkenlerdeki belirsizlikleri katarak sezgisel bulanık kümelere dayalı yeni bir yaklaşım önermişlerdir. Bir endüstrideki 10 tedarikçi firmanın yedi kriter için sezgisel bulanık değerlendirmeleri elde edilmiştir. Tedarikçi 
firmalar kümeleme analizi ile iki kümeye ayrılmış ve en uygun tedarikçi seçim işlemi gerçekleştirilmiştir.

Başkır (2017), müşteri ihtiyaç ve beklentilerini tedarikçi seçim sürecine taşıyan 4aşamalı Bulanık Kalite Fonksiyon Yayılımını önermiştir. Önerilen yöntem, sektörde öncü bir inşaat firmasının bünyesinde yer alan kapı doğrama fabrikasının tedarikçi seçim süreci için uygulanmıştır. Sekiz adet tedarikçi firmanın sıralamaları klasik ve bulanık yaklaşımlar ile belirlenmiştir. Tedarikçi firma verimlilikleri geliştirilen karar ölçütleri ile incelenmiştir. Önerilen 4-aşamalı bulanık kalite fonksiyon yayılımı yaklaşımı sonuçları verimlilik ölçütleri ile desteklenmiştir.

Chang (2019), sezgisel bulanık ağırlıklı ortalama yöntemi ile esnek kümeleri birleştiren yeni bir yaklaşım önermiştir. Önerilen yaklaşım bir imalat işletmesinin tedarikçi seçim süreci için uygulanmıştır. Tedarikçi firma kriterleri; ürün maliyeti, ürün kalitesi, tedarikçi performansı, tedarikçi profili ve risk faktörü olarak belirlenmiştir. Tedarikçi seçim probleminde eksik veriler bulanık ağırlıklı ortalama ve sezgisel bulanık ağırlıklı ortalama yöntemleri ile elde edilmiştir. Değerlendirmeler sonucu, önerilen yöntemin daha etkin olduğu saptanmıştır.

Liu vd. (2019), sürdürülebilir tedarikçi seçim problemi için bulanık üç aşamalı karar verme yaklaşımı önermişlerdir. Birinci aşamada; sürdürülebilir tedarikçi seçim kriterleri belirlenmiştir. İkinci aşamada; aralık değerli sezgisel bulanık sayılar ile entegre kalite fonksiyonu yardımıyla tedarikçi değerlendirme matrisi oluşturulmuştur. Üçüncü aşamada; VIKOR yöntemi ile tedarikçi sıralama ve sınıflandırmaları elde edilmiştir. Önerilen yaklaşım, beş adet tedarikçi firmanın değerlendirildiği sayısal örnek ile anlatılmıştır. Duyarlılık analizi sonuçları önerilen yaklaşımın etkinliğini ortaya koymaktadır.

Nakipoğlu ve Bulgurcu (2020), tedarikçi seçim problemine genişletilmiş sezgisel bulanık TOPSIS yöntemini önermişlerdir. Tekstil firmasında gerçekleştirilen uygulamada, beş adet tedarikçi firma 10 kriter bakımından değerlendirilmiştir. Karar vericilerin tercih ve deneyimlerine göre kriterler ağırlıklandırılmıştır. Önerilen yöntem ile tedarikçi sıralamaları ve en uygun alternatif tedarikçiler belirlenmiştir.

\section{Yöntem}

$\mathrm{Bu}$ bölümde, önerilen bütünleşik yaklaşım teorik altyapısının oluşturulmasında kullanılan yöntemler hakkında bilgiler verilmektedir. 


\subsection{Sezgisel Bulanık Kümeler}

Zadeh (1965) tarafından önerilen bulanık mantık ve ait olma dereceleri ile gerçek yaşam problemlerinde belirsizlik kaynakları analiz edilmekte ve çözümlenmektedir. Bu kapsamda, bir $\hat{A}$ - bulanık kümesindeki elemanın kümeye ait olma derecesi ile ilgilenilmektedir. $X$ evrensel küme olmak üzere bir $\hat{A}$ - bulanık kümesi, $\mu_{\widehat{A}}: X \rightarrow[0,1]$ için $\hat{A}=\left\{\left(x, \mu_{\hat{A}}(x)\right), x \in X\right\}$ biçiminde gösterilir. Bulanık kümelerde bir elemanın üyelik derecesi 1'e yaklaştıkça kümeye aitliği artmakta; üyelik derecesi 0 olduğunda ise kümeye ait olmamaktadır (Dubois ve Prade, 1980; Klir ve Yuan, 1993). Bulanık küme teorisinde bir elemanın kümeye ait olmama derecesi $1-\mu_{\hat{A}}(x)$ ile hesaplanmaktadır. Bulanık $\hat{A}$ kümesinde elemanların üyelik değerleri $\alpha$ 'ya eşit veya $\alpha$ 'dan büyük olanların oluşturduğu kümeye $\alpha$-kesit kümesi denir ve $\hat{A}^{\alpha}=$ $\left\{\left(\forall x \in X \mid \mu_{\hat{A}}(x) \geq \alpha, \quad \alpha \in[0,1]\right)\right\}$ ile gösterilir.

Bulanık kümelerin genelleştirilmiş hali olan sezgisel bulanık kümeler (Atanassov, 1986), karar alma süreçlerinde insan düşünce yapısı kaynaklı belirsizlikleri detaylı ve daha gerçekçi bir şekilde ele almaktadır. Sezgisel bulanık küme teorisinde bulanık kümelerden farklı olarak ait olma ve ait olmama dereceleri birlikte incelenmektedir. $\mathrm{Bu}$ durum, gerçek yaşam problemlerindeki belirsizliğin daha detaylı değerlendirilmesine olanak sağlamaktadır (Atanassov, 1999).

Tanım 1. $X$ boş olmayan evrensel küme olmak üzere, $\tilde{A}=\left\{\left\langle x, \mu_{\tilde{A}}, v_{\tilde{A}}\right\rangle: x \in X\right\}$ sezgisel bulanık küme olsun. Burada, ait olma ve ait olmama dereceleri, sirasıyla, $\mu_{\tilde{A}}: X \rightarrow[0,1]$ ve $v_{\tilde{A}}: X \rightarrow[0,1]$ olarak tanımlanmaktadır. Sezgisel bulanık küme kuramında, bulanık kümelerden farklı olarak ait olma ve ait olmama derecelerinin toplamı 1'den küçüktür (Atanassov,1986).

$0 \leq \mu_{\tilde{A}}(x)+v_{\tilde{A}}(x) \leq 1$

Tanım 2. $x$ elemanının $\tilde{A}$ - sezgisel bulanık kümesine ait olup olmamasındaki belirsizlik, tereddütlük durumu $\pi_{\tilde{A}}(x)$ ile gösterilmektedir. Küçük $\pi_{\tilde{A}}(x)$ değerleri, $x$ elemanı hakkındaki bilginin daha kesin olduğunun göstergesidir (Atanassov, 1999).

Bir $\tilde{A}-$ sezgisel bulanık kümesi için ait olma derecesi $\left(\mu_{\tilde{A}}(x)\right)$, ait olmama derecesi $\left(v_{\tilde{A}}(x)\right)$ ve tereddütlük derecesi $\pi_{\tilde{A}}(x)$ toplamı 1'e eşittir. Buna göre, tereddütlük derecesi eşitlik (3)'deki gibi elde edilir.

$\mu_{\tilde{A}}(x)+\pi_{\tilde{A}}(x)+v_{\tilde{A}}(x)=1$

$\pi_{\tilde{A}}(x)=1-\mu_{\tilde{A}}(x)-v_{\tilde{A}}(x)$ 


\subsubsection{Sezgisel bulanık sayılar}

$\hat{A}$ - bulanık kümesi, i) Normal bulanık küme, ii) Dışbükey bulanık küme, iii) Destek kümesi sınırlı, iv) $\hat{A}$ 'nın her bir $\alpha$ - kesiti, gerçel sayı doğrusunun kapalı aralığında ise bir bulanık sayı olarak tanımlanmaktadır. Bulanık sayılar bulanık kümelerin özel hali olarak ifade edilmektedir (Pedrycz, 1989; Başkır, 2011). Sezgisel bulanık küme teorisinde sezgisel bulanık sayı ve bazı özellikleri aşağıda verilmektedir:

Tanım 3. $\tilde{A}=\left\{\left\langle x, \mu_{\tilde{A}}, v_{\tilde{A}}>: x \in X\right\}\right.$ sezgisel bulanık kümesi

1. $\tilde{A}$ normal sezgisel bulanık sayı olmak üzere $\mu_{\tilde{A}}(x)=1$ ve $v_{\widetilde{A}}(x)=0$

2. $\mu_{\tilde{A}}(x) \cdot\left(\lambda \cdot x_{1}+(1-\lambda) \cdot x_{1}\right) \geq \min \left\{\mu_{\tilde{A}}\left(x_{1}\right), \mu_{\tilde{A}}\left(x_{2}\right)\right\}$

3. $v_{\tilde{A}}(x) \cdot\left(\lambda \cdot x_{1}+(1-\lambda) \cdot x_{1}\right) \leq \operatorname{maks}\left\{v_{\tilde{A}}\left(x_{1}\right), v_{\tilde{A}}\left(x_{2}\right)\right\}, \forall x_{1}, x_{2} \in X, \lambda \in[0,1]$

ise sezgisel bulanık sayı olarak tanımlanmaktadır (Atanassov,1999).

Tanım 4. $\tilde{A}=\left(m ; s_{1}, s_{2} ; s_{1}^{\prime}, s_{2}^{\prime}\right)_{L R}$ ile tanımlı üçgensel sezgisel bulanık sayısında $s_{1}, s_{1}^{\prime} \in R^{+} U$ $0\left(s_{1}^{\prime}>s_{1}\right)$ ve $s_{2}, s_{2}^{\prime} \in R^{+} \cup 0\left(s_{2}^{\prime}>s_{2}\right)$ sırasıyla, ait olma ve ait olmama derecelerine ilişkin sol ve sağ yayılımları göstermektedir. $\tilde{A}-$ sezgisel bulanık sayısının ait olma ve ait olmama derecelerine ilişsin $\alpha$ - kesitleri Şekil 1. ile verilmektedir (Arefi ve Taheri, 2015).

Şekil 1. $\tilde{A}$ sezgisel bulanık sayısının ait olma ve ait olmama derecelerine ilişkin $\alpha$ - kesit gösterimleri

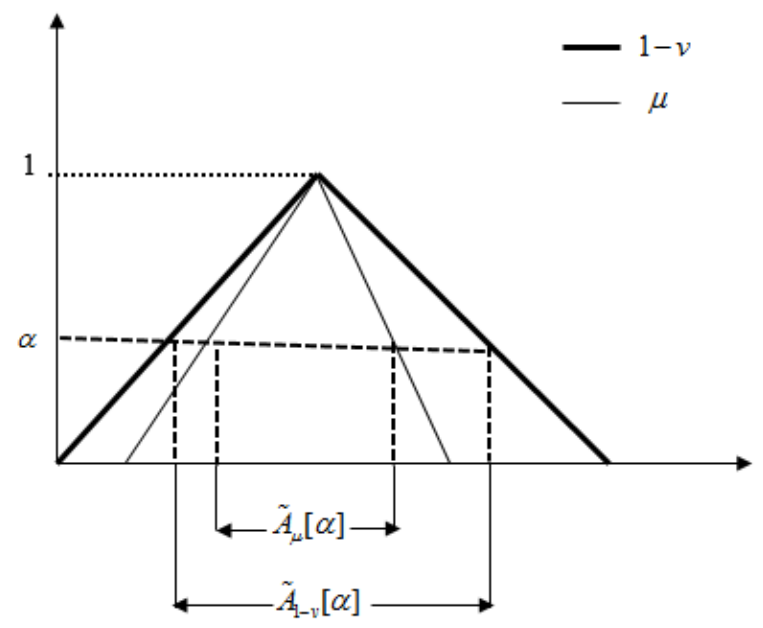

Burada, ait olma ve ait olmama derecelerine ilişkin $\alpha$ - kesitler aşağıda gösterildiği şekilde tanımlanmıştır.

$\tilde{A}_{\mu}[\alpha]=\left\{x: \mu_{\tilde{A}}(x) \geq \alpha\right\}$

$\tilde{A}_{1-v}[\alpha]=\left\{x: 1-v_{\tilde{A}}(x) \geq \alpha\right\}$ 
Tanım 5. $\widetilde{A}$ sezgisel üçgensel bulanık sayısının ait olma ve ait olmama fonksiyonları sırasıyla, Eşitlik (6) ve (7) de tanımlanmıştır.

$$
\begin{aligned}
& \mu_{\tilde{A}}(x)=\left\{\begin{array}{ll}
L\left(\frac{m-x}{s_{1}}\right), & x \leq m \\
R\left(\frac{x-m}{s_{2}}\right), & m<x
\end{array}\right\} \\
& v_{\tilde{A}}(x)=\left\{\begin{array}{ll}
1-L\left(\frac{m-x}{s_{1}^{\prime}}\right), & x \leq m \\
1-R\left(\frac{x-m}{s_{2}^{\prime}}\right), & m<x
\end{array}\right\}
\end{aligned}
$$

\subsection{Klasik ve Bulanık Öbekleme Algoritmaları}

Kümeleme (öbekleme) analizi ile değişken birimleri benzerlikleri bakımından gruplara (kümelere) ayrılmaktadır. Klasik öbeklemede birimler benzerlik durumlarına göre tek bir kümeye atanırken bulanık öbeklemede birimlerin küme atamaları ait olma derecelerine göre gerçekleşmektedir.

$\mathrm{Bu}$ bölümde, klasik ve bulanık öbekleme algoritmaları içerisinde iyi bilinen kortalamalar ve bulanık öbek ortalamaları algoritmaları aktarılmaktadır.

\subsection{1. k-ortalamalar algoritması}

En yaygın kullanılan kümeleme yöntemlerinden biri olan k-ortalamalar algoritması MacQueen (1967) tarafindan geliştirilmiştir. Bu algoritmaya dayalı kümelemede temel amaç küme içi homojen yapının artırılarak, benzer özellikler taşıyan birimlerin en uygun şekilde sınıflandırılmasıdır. k-ortalamalar algoritmasının amaç fonksiyonu Eşitlik (8) ile verilmektedir.

$J^{*}=\sum_{i=1}^{k} \sum_{j=1}^{n}\left\|x_{j}-v_{i}\right\|^{2}$

Burada, $x_{j}: X$ veri kümesindeki $j$. gözlem değeri ve $v_{i}: i$. küme merkezidir. Algoritma adımları aşağıdaki gibidir (Hand vd. 2001).

Algoritma-1. k-ortalamalar algoritması adımları.

Adım 1. $k$ adet küme sayısı, iterasyon sayısı ve $X$ veri kümesinden rastgele başlangıç küme merkezleri $\left(v_{i}\right)$ seçilir.

Adım 2. ( $t=1^{\prime}$ den İter'e) kümeler için aşağıdaki adımlar gerçekleştirilir.

- $i=1,2, \ldots ., k$ için $C_{i}=\left\{x \in X\left\|x-v_{i}\right\| \leq\left\|x-v_{1}\right\|, l=1, \ldots, k ; l=i\right\}$

- Yeni küme merkezleri hesaplanır. 
$i=1,2, \ldots, k$ için $v_{i}=C_{i}$ deki noktaların vektör ortalaması bulunur.

$t=i t e r$ ise DUR.

\subsubsection{Bulanık öbek ortalamaları algoritması}

Bulanık öbeklemede en sık kullanılan algoritmalardan olan bulanık öbek ortalamaları (BÖO) algoritması bir optimizasyon problemi olarak Bezdek (1981) tarafından geliştirilmiştir. Bulanık öbek ortalamaları algoritmasında birimler farklı öbeklere belirli aitlik dereceleri ile üye olabilirler. Amaç, birimlerin ait olma dereceleri yardımıyla en uygun öbeklere ayrılmasıdır. Amaç fonksiyonu Eşitlik (9) ile verilmektedir.

$\min J(u, v)=\sum_{k=1}^{n} \sum_{i=1}^{c} u_{i k}^{m}\left(\left\|x_{k}-v_{i}\right\|\right)_{A}$

$0<u_{i k}<1, \forall i, k ; \sum_{i=1}^{c} u_{i k}=1, \quad \forall k ; 0 \leq \sum_{i=1}^{n} u_{i k} \leq n$

Burada, $m$ : bulanıklık derecesi, $c$ : öbek sayısı, $u_{i k}$ : üyelik derecesi, $x_{k}$ : veri vektörü ve $v_{i}$ :öbek merkezidir. BÖO algoritma adımları aşağıda verilmektedir (Türkşen, 2006).

Algoritma-2. Bulanık öbek ortalamaları algoritma adımları.

Adım 1: $m, c$, iter,$\varepsilon$ belirlenir.

Adım 2: Başlangıç öbek merkezleri rastgele belirlenir.

Adım 3: $t=1$ den iter

Gözlemlerin merkezlere olan uzaklıkları hesaplanır.

$d\left(x_{k}, v_{i}\right)=\left\|x_{k}-v_{i}\right\|$

Eşitlik (9) ile verilen optimizasyon probleminin çözümlerinden biri olan üyelik dereceleri

$u_{i k, t}=\left[\sum_{j=1}^{c}\left(\frac{\left\|x_{k}-v_{i, t-1}\right\|}{\left\|x_{k}-v_{j, t-1}\right\|}\right)^{2 /(m-1)}\right]^{-1}, i \neq j$

ile hesaplanir.

Eşitlik (9) ile verilen optimizasyon probleminin çözümlerinden diğeri olan merkezler

$v_{i, t}=\frac{\sum_{k=1}^{n}\left(u_{i k}\right)^{m} x_{k}}{\sum_{k=1}^{n}\left(u_{i k}\right)^{m}}$

ile hesaplanır.

Eğer, $t=$ iter 
$\left\|v_{i, t}-v_{i, t-1}\right\| \leq \varepsilon$ ise DUR

Denetimsiz bulanık öbekleme algoritması olan BÖO algoritması ile veri ve belirsizlikleri için en iyi bulanık parçalanma (üyelik değerleri matrisi) seçiminde geliştirilmiş öbek geçerlik indekslerinden yararlanılmaktadır. Bu çalışmada, Xie-Beni tarafından geliştirilmiş Eşitlik (10) ile verilen öbek geçerlik indeksinden yararlanılmıştır.

$V_{X B}(u)=\left\{\frac{\sum_{i=1}^{c} \sum_{k=1}^{n} u_{i k}^{m}\left\|x_{k}-v_{i}\right\|^{2}}{n\left(\min _{i \neq j}\left\{\left\|v_{i}-v_{j}\right\|^{2}\right\}\right)}\right\}$

\section{3. Önerilen Sezgisel Bulanık Yaklaşım}

$\mathrm{Bu}$ bölümde, tedarikçi seçimi ve değerlendirmeleri için önerilen sezgisel bulanık kümelere dayalı bütünleşik yaklaşım ve adımları açıklanmaktadır. Önerilen yaklaşım nitel ve nicel değerlendirmeleri içeren karma bir yapıdadır. Nitel kısımda, karar vericiler tedarikçi firmaları seçim kriterlerine göre değerlendirmektedir. Nicel kısımda ise işletmenin mevcut değerlendirme sistemi ile hesaplanan tedarikçi puanlarına ilişkin değerlendirmeler yer almaktadir.

Günümüz rekabet ortamı işletmelerin müşteri memnuniyetini hızlı ve etkin bir biçimde karşılamasını gerektirmektedir. Bu nedenle, işletmeler çok sayıda tedarikçi ile üretim/hizmet süreçlerini gerçekleştirmektedir. Önerilen yaklaşımda çok sayıda tedarikçinin karma değerlendirme yapısı klasik ve bulanık kümeleme (öbekleme) algoritmaları kullanılarak sınıflandırılmaktadır. Böylece, karma değerlendirmeler bakımından benzer ve/veya benzer olmayan tedarikçiler gruplandırılarak, işletmelere öncelikli olarak çalışacakları tedarikçileri belirleme imkanı sunulmaktadır. Önerilen yaklaşım ile nitel değerlendirmeler ve belirsizlikleri için sezgisel bulanık kümelere dayanan değerlendirmeler sayesinde karar verici yargısı daha gerçekçi ele alınmakta, karma (nitel ve nicel) değerlendirmeler ile işletmelere tedarikçilerini kapsamlı bir şekilde değerlendirme imkanı sunulmakta, kümeleme (öbekleme) analizi kullanarak çok sayıda tedarikçi karma değerlendirme durumlarını ortaya koyan gruplara (kümelere) göre incelenmektedir.

Önerilen sezgisel bulanık yaklaşımın tedarikçi seçim problemi için akış şeması Şekil 2 ile verilmektedir. 
Şekil 2. Önerilen sezgisel bulanık yaklaşım adımları akış şeması

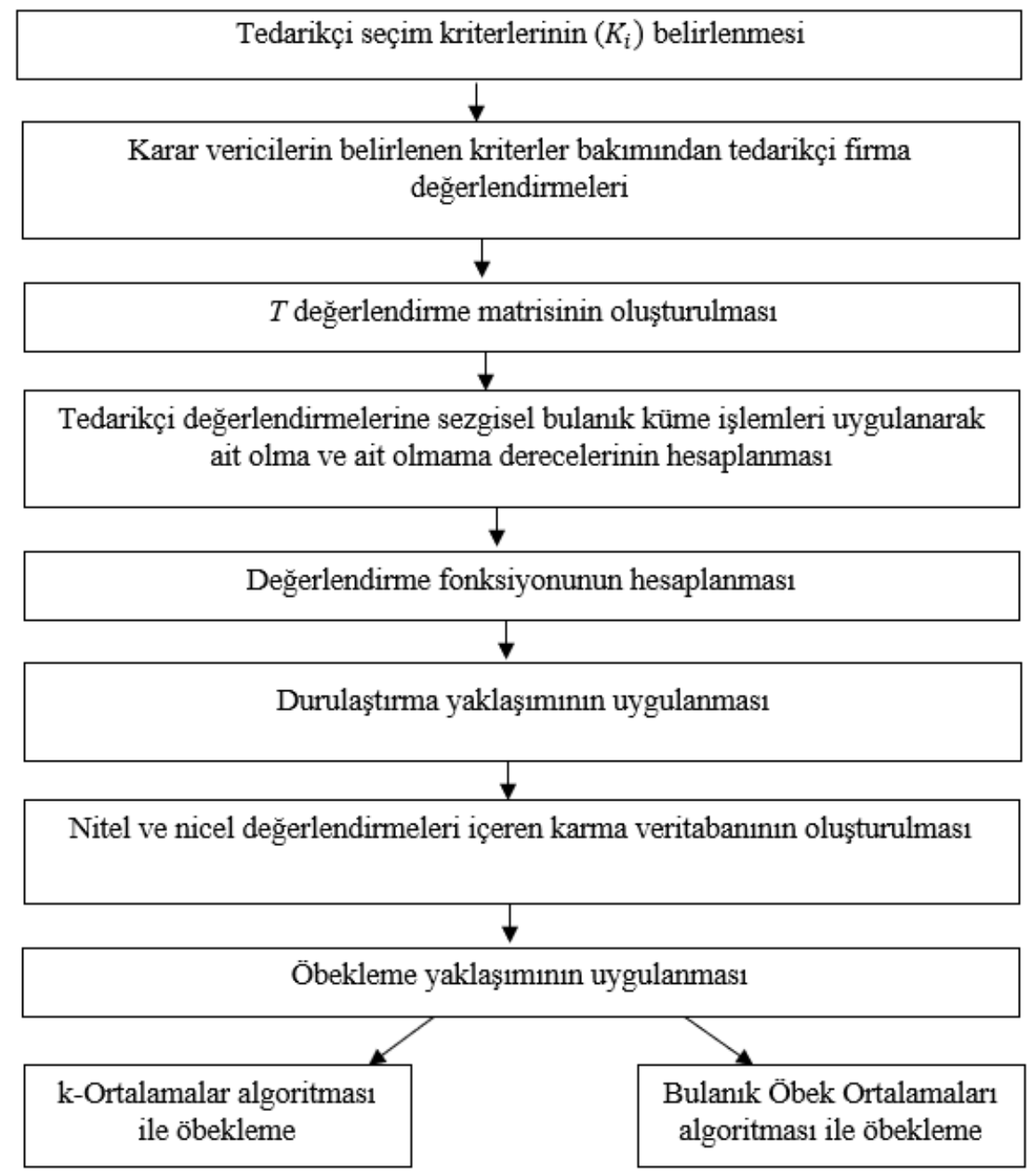

Şekil 2’de verilen önerilen yaklaşım adımları aşağıda açıklanmaktadır.

Adım 1. Tedarikçi seçim kriterleri $K_{i}(i=1,2, \ldots ., k)$ belirlenir.

Adım 2. Karar vericiler belirlenen kriterler bakımından tedarikçi firmaları değerlendirir ve $T$ değerlendirme matrisi oluşturulur. Burada, $f_{i j}: j$. kriter için $i$. tedarikçi değerlendirmesidir.

$T=\left[\begin{array}{cccc}f_{11} & f_{12} & \ldots & f_{1 k} \\ \vdots & \vdots & \vdots & \vdots \\ f_{m 1} & f_{m 2} & \ldots & f_{m k}\end{array}\right]$

Adım 3. Tedarikçi değerlendirmelerine sezgisel bulanık küme işlemleri uygulanarak ait olma ve ait olmama dereceleri sırasıyla, Eşitlik (11) ve (12) yardımıyla hesaplanır (Sotirova vd, 2014).

$\mu_{i j}=\frac{f_{i j}}{f_{m a k s}}$ 
$v_{i j}=\left\{\begin{array}{cl}\frac{f_{\min }-f_{i j}}{f m a k s}, & f_{\text {min }} \geq f_{i j} \\ 0, & f_{\text {min }}<f_{i j}\end{array}\right\}$

Burada, $f_{i j}$ : j. tedarikçi için $i$. kriter değerlendirmesi; $f_{m a k s}$ : Bir tedarikçinin $i$. kriterde aldı $\breve{g} 1$ maksimum değer; $f_{\min }$ Bir tedarikçinin $i$. kriterde alması gereken en küçük değerdir.

Adım 4. Değerlendirme fonksiyonu Eşitlik (13) kullanılarak hesaplanır.

$E\left(M_{i}\right)=\left(\left(\left(\mu_{i j}, v_{i j}\right) \Lambda\left(\mu_{i k}, v_{i k}\right) \cdots\left(\mu_{i p}, v_{i p}\right)\right) \mathrm{V}\left(\mu_{i s}, v_{i s}\right)\right)$

Burada, $\Lambda$ ve V sırasıyla, kesişim ve birleşim operatörleridir. Değerlendirme fonksiyonundaki ait olma ve olmama dereceleri Eşitlik (14) ve (15) kullanılarak hesaplanır.

$$
\begin{aligned}
& \mu_{M_{i}}=\operatorname{maks}\left(\min \left(\mu_{i j}, \mu_{i k}, \cdots, \mu_{i p}\right),\left(\mu_{i s}\right)\right) \\
& v_{M_{i}}=\min \left(\operatorname{maks}\left(v_{i j}, v_{i k}, \cdots, v_{i p}\right),\left(v_{i s}\right)\right)
\end{aligned}
$$

$\mathrm{Bu}$ eşitliklerin hesaplama adımları aşağıdaki gibidir:

- Başlangıçta bir kriterin $\mu_{i s}$ ait olma (veya $v_{i s}$ ait olmama) derecesi sabit olarak seçilir.

- Geriye kalan kriterlere ilişkin $\mu_{i j}$ ait olma (veya $v_{i j}$ ait olmama) dereceleri arasından minimum (maksimum) olan belirlenir.

- 2. adımda belirlenen minimum $\mu_{i j}$ ait olma (veya maksimum $v_{i j}$ ait olmama) derecesi ile sabit olarak seçilen kritere ait $\mu_{i s}$ (veya $v_{i s}$ ) arasından en büyüğü (en küçüğü) belirlenir.

Adım 5. Tedarikçilerin kesin değerlendirme işlemlerini yapabilmek için sezgisel bulanık küme değerlendirmeleri (16) ile verilen eşitlikle durulaştırılır.

$H(A)=\mu_{A}(x)+v_{A}(x)$

Burada, $\mu_{A}(x)$ ve $v_{A}(x)$ değerlendirme fonksiyonu ile elde edilen ait olma ve ait olmama değerleridir.

Adım 6. Nitel/nicel tedarikçi değerlendirmeleri için durulaştırma işlemi sonucunda elde edilen H değerleri ile karma değerlendirme veritabanı oluşturulur. Klasik ve bulanık öbekleme algoritmaları kullanılarak tedarikçi sıralama ve sınıflandırmaları gerçekleştirilir. Bulanık öbekleme sonucu her bir öbek (küme) için elde edilen ait olma (üyelik) derecelerinin durulaştırma işlemi, bölüm 2.1'de verilen bir bulanık küme için $\alpha$ - kesit küme tanımına göre $\alpha=0,5$ olmak üzere ilgili öbek üyelik değerleri 0,5 'e eşit veya 0,5 'den büyük olacak biçimde yapilır. 
Önerilen sezgisel bulanık yaklaşımda $H$-değerlerinin hesaplama adımları için sayısal örnek aşağıda verilmektedir:

\section{Sayısal Örnek :}

Tablo 1. Karar verici öznel değerlendirmeleri

Tablo 2. Ait olma dereceleri

Tablo 3. Ait olmama dereceleri

Tablo 4. E ve H değerleri

\begin{tabular}{l|llllll}
\hline \multicolumn{1}{l}{} & $\mathrm{K}_{1}$ & $\mathrm{~K}_{2}$ & $\mathrm{~K}_{3}$ & $\mathrm{~K}_{4}$ & $\mathrm{~K}_{5}$ & $\mathrm{~K}_{6}$ \\
\hline $\mathrm{T} 1$ & 6 & 2 & 7 & 3 & 4 & 4 \\
$\mathrm{~T} 2$ & 2 & 3 & 2 & 3 & 4 & 5 \\
$\mathrm{~T} 3$ & 2 & 2 & 4 & 1 & 4 & 5 \\
$\mathrm{~T} 4$ & 2 & 2 & 4 & 7 & 5 & 4 \\
$\mathrm{~T} 5$ & 2 & 2 & 1 & 1 & 4 & 5 \\
$\mathrm{~T} 6$ & 6 & 2 & 1 & 7 & 4 & 4 \\
$\mathrm{~T} 7$ & 2 & 3 & 7 & 7 & 4 & 5 \\
$\mathrm{~T} 8$ & 7 & 3 & 7 & 7 & 3 & 5 \\
$\mathrm{~T} 9$ & 7 & 4 & 4 & 4 & 5 & 5 \\
$\mathrm{~T} 10$ & 5 & 3 & 4 & 7 & 3 & 7 \\
\hline
\end{tabular}

\begin{tabular}{c|llllll}
\hline & $\mathrm{K}_{1}$ & $\mathrm{~K}_{2}$ & $\mathrm{~K}_{3}$ & $\mathrm{~K}_{4}$ & $\mathrm{~K}_{5}$ & $\mathrm{~K}_{6}$ \\
\hline $\mathrm{T} 1$ & 0,857 & 0,5 & 1 & 0,429 & 0,571 & 0,571 \\
$\mathrm{~T} 2$ & 0,286 & 0,75 & 0,286 & 0,429 & 0,571 & 0,714 \\
$\mathrm{~T} 3$ & 0,286 & 0,5 & 0,571 & 0,143 & 0,571 & 0,714 \\
$\mathrm{~T} 4$ & 0,286 & 0,5 & 0,571 & 1 & 0,714 & 0,571 \\
$\rightarrow \mathrm{T} 5$ & 0,286 & 0,5 & 0,143 & 0,143 & 0,571 & 0,714 \\
$\mathrm{~T} 6$ & 0,857 & 0,5 & 0,143 & 1 & 0,571 & 0,571 \\
$\mathrm{~T} 7$ & 0,286 & 0,75 & 1 & 1 & 0,571 & 0,714 \\
$\mathrm{~T} 8$ & 1 & 0,75 & 1 & 1 & 0,429 & 0,714 \\
$\mathrm{~T} 9$ & 1 & 1 & 0,571 & 0,571 & 0,714 & 0,714 \\
$\mathrm{~T} 10$ & 0,714 & 0,75 & 0,571 & 1 & 0,429 & 1 \\
\end{tabular}

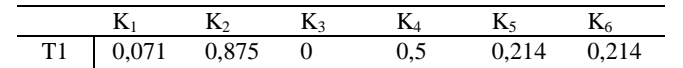

$\mathrm{T} 2 \quad 0,643 \quad 0,625 \quad 0,643 \quad 0,5 \quad 0,214 \quad 0,071$

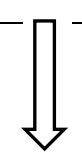

Eşitlik (11) ile ait olma dereceleri hesaplanır.

Örneğin,

$$
\mu_{11}=\frac{6}{7}=0,857
$$

Eşitlik (12) ile ait olmama dereceleri hesaplanır.

Örneğin,

\begin{tabular}{|c|c|c|c|c|c|c|c|c|c|}
\hline $\begin{array}{l}K_{1} \\
0,071\end{array}$ & $\begin{array}{l}\mathrm{K}_{2} \\
0,875\end{array}$ & $\begin{array}{l}\mathrm{K}_{3} \\
0\end{array}$ & $\begin{array}{l}\mathrm{K}_{4} \\
0,5\end{array}$ & $\begin{array}{l}\mathrm{K}_{5} \\
0,214\end{array}$ & $\begin{array}{l}\mathrm{K}_{6} \\
0,214\end{array}$ & \multicolumn{2}{|r|}{$\begin{array}{l}\text { Ait olma } \\
\text { E-değeri }\end{array}$} & $\begin{array}{l}\text { Ait olmama } \\
\text { E-değeri }\end{array}$ & \multirow{2}{*}{$\frac{\mathrm{H}}{1}$} \\
\hline 0643 & 0,625 & 0.643 & 0.5 & 0.214 & 0.071 & $\mathrm{~T} 1$ & 1 & 0 & \\
\hline & & & & & & $\mathrm{T} 2$ & 0,286 & 0,643 & 0,929 \\
\hline 0,643 & 0,875 & 0,357 & $\begin{array}{l}0, / 86 \\
0\end{array}$ & $\begin{array}{l}0,214 \\
0,071\end{array}$ & 0,214 & $\mathrm{~T} 3$ & 0,571 & 0,357 & 0,928 \\
\hline 0,643 & 0,875 & 0,786 & 0,786 & 0,214 & 0,071 & $\mathrm{~T} 4$ & 0,571 & 0,357 & 0,928 \\
\hline $\begin{array}{l}0,071 \\
0,643\end{array}$ & $\begin{array}{l}0,875 \\
0,625\end{array}$ & $\begin{array}{l}0,786 \\
0\end{array}$ & $\begin{array}{l}0 \\
0\end{array}$ & $\begin{array}{l}0,214 \\
0,214\end{array}$ & $\begin{array}{l}0,214 \\
0,071\end{array}$ & T5 & 0,143 & 0,786 & 0,929 \\
\hline & & & & & & T6 & 0,571 & 0,214 & 0,785 \\
\hline 0 & 0,625 & 0 & 0 & 0,357 & 0,071 & $\mathrm{~T} 7$ & 1 & 0 & 1 \\
\hline 0 & 0,375 & 0,357 & 0,357 & 0,071 & 0,071 & T8 & 1 & 0 & 1 \\
\hline 0,214 & 0,625 & 0,357 & 0 & 0,357 & 0 & T9 & 0,571 & 0,357 & 0,928 \\
\hline & & & & & & T10 & 0,571 & 0,357 & 0,928 \\
\hline
\end{tabular}

$$
v_{11}=\frac{6,5-6}{7}=0,071
$$

Üçüncü kriter sabit iken Eşitlik (14) ve (15) ile $E$ değerleri hesaplanır.

Örneğin, T1 için;

$$
\begin{aligned}
& \mu_{M_{1}}=\operatorname{maks}(\min (0,8570,50,4290,5710,571),(1))=1 \\
& v_{M_{1}}=\min (\operatorname{maks}(0,0710,8750,50,2140,214),(0))=0
\end{aligned}
$$




\section{Uygulama}

Çalışmanın bu bölümünde, inşaat sektöründe faaliyet gösteren bir işletmenin tedarikçi seçim problemi için sezgisel bulanık kümelere dayalı bütünleşik yaklaşım sonuçları verilmektedir.

Tedarikçi seçimi ile ilgili ilk çalışmayı gerçekleştiren Dickson (1966), ürün kalitesi, zamanında teslim, fiyat, garanti politikası, esneklik başta olmak üzere 23 adet seçim kriteri belirlemiştir. Al-Faraj vd. (1993) tedarikçi seçimi için kalite, fiyat, teslimat, teknik yeterlilik, performans geçmişi gibi kriterleri ele almışlardır. Liao (2010), fiyat, kalite, zamanında teslim ve hizmet kriterlerinin en önemli tedarikçi seçim kriterlerinden olduğunu belirtmiştir. Kaur ve Pal (2015) çalışmasında, fiyat, kalite, teslimat zamanı, hizmet vb. yedi kriter belirlemişlerdir. Evans (1980), Shipley (1985), Ho vd. (2010) fiyat kalite ve zamanında teslim kriterlerinin en önemli ve yaygın kullanılan tedarikçi seçim kriterleri olduğunu ifade etmiştir. Günümüz işletmeleri için kalite, fiyat, zamanında teslim öncelikli olarak değerlendirilen tedarikçi seçim kriterleridir. Bu çalışmada önerilen yaklaşımın uygulaması için bir inşaat firmasının tedarik seçim ve değerlendirmelerinde etkili üç karar verici ile çalışılmıştır. Bu karar vericiler uzmanlık alanlarına göre işletmenin mali ve idari işler sorumlusu, satın alma sorumlusu ve proje yürütümü sorumlusudur. Karar vericilerin işletme gereksinimlerine yönelik görüşleri ile tedarikçi seçim kriterleri sıkça kullanılan kalite, fiyat ve teslimin yanı sıra verimlilik, hizmet ve esneklik olarak belirlenmiştir.

İşletmenin 108 adet tedarikçi firması karar vericiler tarafından değerlendirilmiştir. Karar verici öznel değerlendirmelerinde tedarikçinin bir kriteri sağlama durumu için $1 \rightarrow$ çok kötüden $7 \rightarrow$ çok yükseğe değişen 7'li likert ölçeği kullanılmıştır. Bu öznel değerlendirmeler ve belirsizlikleri için hesaplamalar sezgisel bulanık kümelerle gerçekleştirilmiştir. Ayrıca, her bir karar vericinin mevcut tedarikçi-değerlendirme sistemi puanları için sezgisel bulanık küme hesaplamaları yapılmıştır. Eşitlik (16) ile sezgisel bulanık değerlendirmelerin durulaştırması yapılmış ve H-değerleri elde edilmiştir. Karar vericilerin öznel ve nesnel sezgisel bulanık değerlendirmeleri ile karma veritabanı oluşturulmuştur. 108×6 boyutlu H-karma veritabanı genel gösterimi Şekil 3 'teki gibidir. 
Şekil 3. $108 \times 6$ boyutlu karma veritabanı genel gösterimi

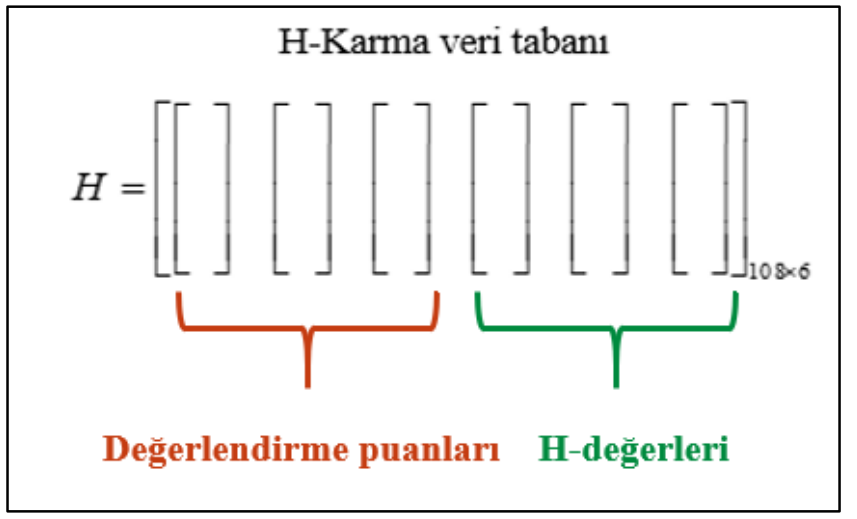

Sezgisel bulanık kümelere dayalı değerlendirmeler için durulaştırma sonrası karar vericilerin kesin değerlendirmelerini içeren karma veritabanı klasik ve bulanık kümeleme (öbekleme) algoritmaları kullanılarak sınıflandırılmıştır. Bulanık öbekleme sonucu elde edilen öbek-üyelik değerleri 0,5 ' den büyük eşit olacak şekilde durulaştırılarak kesin öbekleme sonuçları belirlenmiştir.

İşletme karar vericilerinin öznel ve nesnel değerlendirmeleri için önerilen yöntem hesaplamalarında kullanılan minimum değerler Tablo 5 ve Tablo 6'da verilmektedir.

Tablo 5. Kriterlerin alması gereken minimum değerler

\begin{tabular}{cccccc}
\hline Kalite & Teslim & Fiyat & Verimlilik & Servis & Esneklik \\
\hline 6,5 & 5,5 & 6,5 & 6,5 & 5,5 & 5,5 \\
\hline
\end{tabular}

Tablo 6. Tedarikçi puanları için her bir karar vericiye ait minimum değerler

\begin{tabular}{ccc}
\hline $\mathrm{KV}-1$ & $\mathrm{KV}-2$ & $\mathrm{KV}-3$ \\
\hline 75 & 80 & 85 \\
\hline
\end{tabular}

Tedarikçi firmaların sezgisel bulanık değerlendirmelerini içeren $108 \times 6$ boyutlu karma veritabanı için kümeleme (öbekleme) algoritmaları uygulanmıştır. Bu karma veritabanı için BÖO algoritması sonucu en iyi bulanık parçalanma Xie-Beni (1991) geçerlik indeksine göre öbek sayısı $(c)$ : 2 ve bulanıklık derecesi $(m)$ : 1,8 alınarak belirlenmiştir. Xie-Beni geçerlik indeksi sonuçları Tablo 7'de verilmektedir. 
Tablo 7. Xie-Beni geçerlik indeksi sonuçları

\begin{tabular}{c|ccccccc}
\hline \multicolumn{1}{l|}{$\mathrm{mlc}$} & 2 & 3 & 4 & 5 & 6 & 7 & 8 \\
\hline 1,4 & 0,1562 & 0,2723 & 0,6522 & 0,1343 & 0,4593 & 0,3496 & 0,3252 \\
1,6 & 0,1469 & 0,2735 & 0,6375 & 0,4852 & 0,3640 & 0,3179 & 0,2276 \\
1,8 & 0,1434 & 0,2896 & 0,6413 & 0,5156 & 0,3455 & 0,4535 & 0,2107 \\
2,0 & 0,1460 & 0,3166 & 0,6522 & 0,5029 & 0,7091 & 0,4197 & 0,4332 \\
2,2 & 0,1537 & 0,3534 & 0,6655 & 0,5910 & 0,7602 & 0,2598 & 0,3714 \\
2,4 & 0,1649 & 0,3995 & 0,6818 & 0,6566 & 0,6751 & 0,6324 & 0,4269 \\
2,6 & 0,1783 & 0,4556 & 0,7004 & 0,7141 & 0,7056 & 0,4704 & 0,4439 \\
\hline
\end{tabular}

Karma veritabanı için BÖO algoritması sonucu öbekleme yapısı \%99,1; k = 2 olmak üzere k-ortalamalar algoritması sonucu öbekleme yapısı \%94,4 doğruluk oranına sahiptir. BÖO algoritması sonucunda her bir öbeğe ait üyelik dereceleri 0,5 'den büyük eşit olacak şekilde yapılan durulaştırma işlemi Şekil 4'de gösterilmektedir.

Şekil 4. Karma veritabanı için BÖO algoritması öbekleme sonuçları

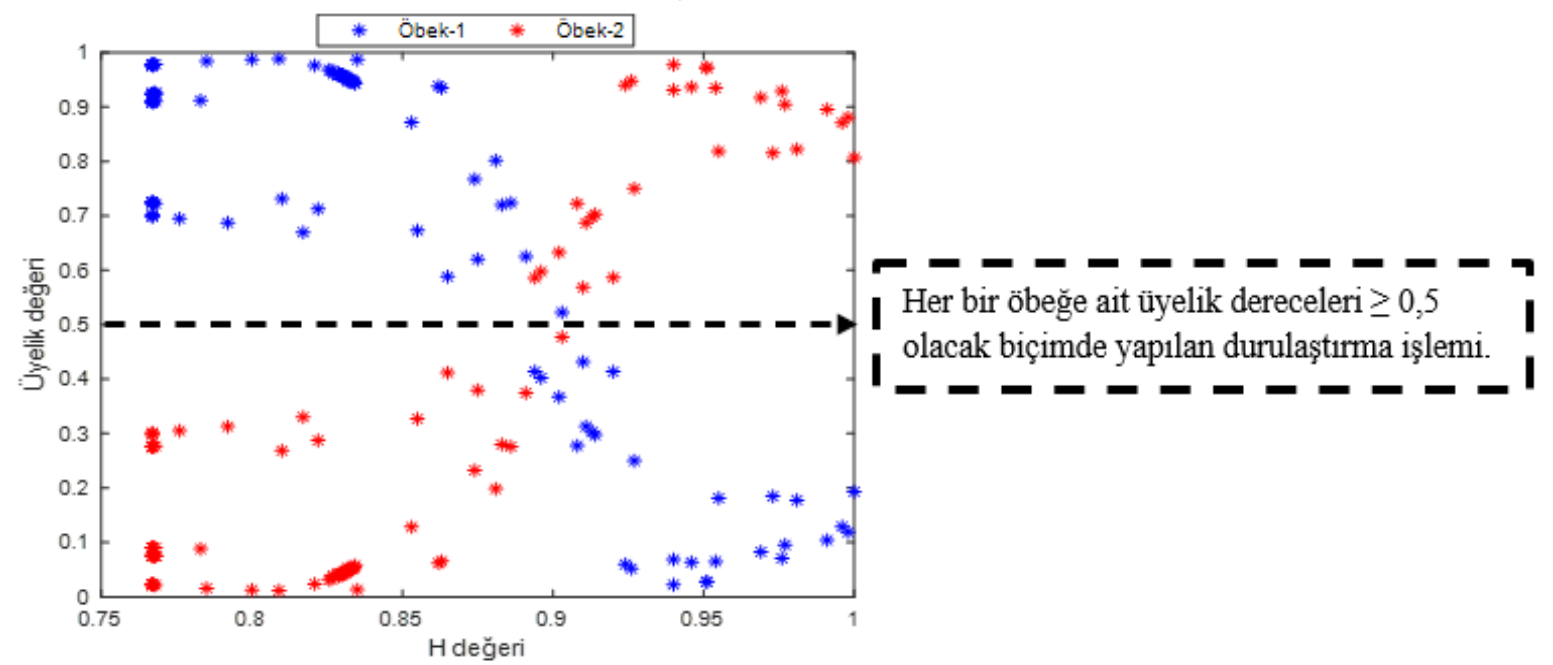

Karma veritabanı ile elde edilen klasik ve bulanık öbekleme sonuçları ile sadece işletmenin karar almada kullandığı tedarikçi puanları sınıflandırmasına ilişkin bazı önemli bulgular Tablo 8'de verilmektedir.

Tablo 8. Klasik ve bulanık öbekleme için çapraz doğrulama sonuçları

$$
\text { Çapraz doğrulama sonucu }
$$

sınıflandırma hatalarına ilişkin

tedarikçi sayıları

\begin{tabular}{lccl}
\hline & Öbek-1 & Öbek-2 & Doğruluk Oranı (\%) \\
k-ortalamalar & 16 & 12 & $\% 74,1$ \\
Bulanık öbek ortalamaları & 10 & 0 & $\% 90,7$ \\
\hline
\end{tabular}


Karma veritabanında sadece işletmenin tedarikçi puanları için k-ortalamalar algoritması doğruluk oranı \%74,1 bulunmuştur (bkz. Tablo 8). Öbek-1'de 16, Öbek-2'de 12 tedarikçi firma doğru sınıflandırılamamıştır. Doğru sınıflandırılamayan tedarikçiler ve puanları Tablo 9'daki gibidir.

Tablo 9. k-ortalamalar algoritması sonucu doğru sınıflandırılmayan tedarikçiler ve puanları

\begin{tabular}{c|ccccccccc}
\hline & T7 & T61 & T69 & T9 & T18 & T28 & T44 & T22 \\
\cline { 2 - 9 } Öbek-1 & 83,3992 & 83,6068 & 84,2694 & 84,355 & 85,4582 & 85,5422 & 86,1024 & 86,3026 \\
\cline { 2 - 9 } & T43 & T20 & T37 & T65 & T54 & T46 & T45 & T55 \\
\cline { 2 - 9 } & 86,565 & 87,0901 & 88,2678 & 88,9127 & 89,8877 & 93,3775 & 95,9042 & 97,7433 \\
\hline \multirow{3}{*}{ Öbek-2 } & T19 & T42 & T78 & T70 & T64 & T59 & T12 & T21 \\
\cline { 2 - 9 } & 62,5027 & 62,6899 & 67,1717 & 68,7062 & 68,7253 & 70,2139 & 72,4121 & 73,8312 \\
\cline { 2 - 9 } & T50 & T63 & T68 & T72 & & & & \\
\cline { 2 - 9 } & 73,953 & 75,8311 & 77,4136 & 79,8461 & & & & \\
\hline
\end{tabular}

Tablo 9 ile belirlenen 28 tedarikçi firma doğru sınıflandırılırsa Öbek-1 puan aralığı: 62,5027-80,3092 ve Öbek-2 puan aralığ1: 81,5705-97,7433 olarak bulunur.

Karma veritabanında sadece işletmenin tedarikçi puanları için BÖO algoritması sonucu doğruluk oranı \%90,7 olarak bulunmuştur (bkz. Tablo 8). BÖO ile doğru sınıflandırılamayan 10 tedarikçi firma, aldıkları puanlar ve bulundukları öbekler ile Tablo 10'da verilmektedir.

Tablo 10. BÖO algoritması sonucu doğru sınıflandırılmayan tedarikçiler

\begin{tabular}{ccccccccccc}
\hline & T69 & T9 & T62 & T18 & T28 & T44 & T22 & T43 & T20 & T37 \\
\hline Puan & 84,2694 & 84,355 & 84,5968 & 85,4582 & 85,5422 & 86,1024 & 86,3026 & 86,565 & 87,0901 & 88,2678 \\
Öbek & 1 & 1 & 1 & 1 & 1 & 1 & 1 & 1 & 1 & 1 \\
\hline
\end{tabular}

Tablo 10 ile belirlenen 10 tedarikçi firma doğru sınıflandırılırsa puan aralıkları Öbek-1 için 62,5027- 83,6068, Öbek-2 için 84,2694- 97,7433 olarak bulunur. 


\section{Sonuçlar}

Küreselleşme ile artan talepleri en iyi düzeyde karşılama ve rekabet koşullarına ayak uydurma hedefindeki işletmeler için tedarikçi seçim ve değerlendirmeleri önemli bir yere sahiptir. İşletmeler mevcut tedarikçi seçim süreçlerini bilimsel yaklaşımlarla geliştirmeye odaklanmaktadır. Bu çalışmada, inşaat sektöründe faaliyet gösteren bir işletmenin tedarikçi seçimi süreci için sezgisel bulanık kümelere dayalı bir yaklaşım önerilmiştir. İşletme bünyesinde bulunan etkin karar vericilerin i) kalite, ii) fiyat, iii) teslimat, iv) verimlilik, v) hizmet, vi) esneklik olarak tanımlanan ekonomik kriterlere dayalı öznel değerlendirmeleri ile mevcut değerlendirme puanları birleştirilerek karma değerlendirme sistemi oluşturulmuştur. Bu karma sistemde 108 adet tedarikçi için karar verici sezgisel bulanık küme değerlendirmelerini içeren veritabanı ile öbekleme (kümeleme) çalışmaları gerçekleştirilmiştir. Öbekleme (kümeleme) analizi ile işletme tedarikçilerinin klasik ve bulanık küme yapılarının doğruluğu karşılaştırılmıştır. İşletmenin mevcut tedarikçi değerlendirme puanlarının önerilen yaklaşım ile oluşan klasik ve bulanık kümelerdeki atanma durumları belirlenmiştir. Karma veritabanının klasik ve bulanık öbekleme algoritmaları sonucu sınıflandırma yapıları, sırasıyla, k-ortalamalar algoritması için \%94,4 ve BÖO algoritması için \%99,1 olarak bulunmuştur. Karma veritabanı için önerilen yaklaşım sonuçları sadece işletmenin belirlediği tedarikçi puanları bakımından incelenmiştir. Tedarikçi puanlarına göre BÖO algoritması sonucu oluşan öbek yapılarının \%90,7 ve k-ortalamalar algoritması sonucu oluşan öbek yapılarının ise \%74,1 doğruluğa sahip olduğu belirlenmiştir. Buna göre, tedarikçi seçim problemi için BÖO algoritması ile Öbek-1 değerlendirme puan aralığı: 62,5027 - 88,2678 Öbek-2 puan aralı̆̆1: 87,4089 - 97,7433 olarak önerilmiştir. Belirlenen puan aralıklarına göre, ikinci öbek işletmenin öncelikli olarak tercih edebileceği tedarikçileri göstermektedir. Önerilen yaklaşımla tedarikçi değerlendirmelerinde üçüncü karar vericinin sezgisel bulanık değerlendirmeler için belirlediği minimum puanı (bkz Tablo 6) alan tedarikçiler ikinci öbekte yer almıştır. Diğer karar vericilerin önerdikleri minimum puanlar (bkz Tablo 6) ise sezgisel bulanık kümeler ile karar verici öznel değerlendirmelerinde etkisini göstermiştir. BÖO algoritması ile öbekleme çalışmaları yüksek doğruluk oranlarına sahiptir. Önerilen yaklaşımda sezgisel bulanık kümelere dayanan hesaplamalar ile birlikte bulanık öbekleme kullanımı klasik öbeklemeye göre daha hassas ve etkin bir tedarikçi seçim sürecini ortaya koymuştur.

İlerideki çalışmalarda, sağlık, mühendislik, ekonomi, eğitim alanlarına yönelik personel seçimi, performans değerlendirmeleri gibi farklı seçim ve değerlendirme problemleri için önerilen yaklaşımın etkisi incelenebilir. Ayrıca, önerilen yaklaşımda gerçek yaşama özgü karar problemleri için karar verici ve kriter sayısı çeşitlendirilebilir. 


\section{Kaynakça}

Al-Faraj, T. N., Alidi, A. S., and Al-Zayer, J. A. (1993). Vendors selection via a spreadsheet analytical hierarchy process. Computers and Industrial Engineering, 25(1-4), 65-68.

Atanassov, K. (1986). Intuitionistic fuzzy sets. Fuzzy Sets and Systems, 20, 87-96.

Atanassov, K. (1999). Intuitionistic fuzzy sets: theory and applications. Heidelberg, Germany: Physica-Verlag, 1-50.

Arefi, M. and Taheri, S. M. (2015). Least-squares regression based on Atanassov's intuitionistic fuzzy inputs outputs and Atanassov's intuitionistic fuzzy parameters. IEEE Transactions on Fuzzy Systems, 23(4), 1142-1154.

Başkır, M. B. (2011). Bulanık kalite fonksiyon yayılımı yaklaşımının iyileştirilmesi ve uygulamaları. Doktora Tezi, Ankara Üniversitesi, Fen Bilimleri Enstitüsü, Ankara.

Başkır, M. B. (2017). 4-Aşamalı Bulanık Kalite Fonksiyon Yayılımı Yaklaşımı ile Tedarikçi Seçimi, Verimlilik Dergisi, 2017/4, 81-110.

Bezdek, J.C. 1981. Pattern recognition with fuzzy objective function algorithms. Plenum Press, 256 p., New York.

Boran, F. E., S. Genc, M. Kurt and D. Akay (2009). A multi-criteria intuitionistic fuzzy group decision making for supplier selection with TOPSIS method. Expert Systems with Applications, 36, 11363-11368.

Boran, F. E. (2011). An integrated intuitionistic fuzzy multicriteria decision making method for facility location selection. Mathematical and Computational Applications, 16 (2), 487-496.

Chang, K.H. (2019). A novel supplier selection method that integrates the intuitionistic fuzzy weighted averaging method and a soft set with imprecise data. Annals of Operations Research, 272, 139-157.

Dickson, G. W. (1966). An analysis of vendor selection system and decisions. Journal of purchasing, 2(1), 28-41.

Dubois, D. and Prade, H. (1980). Fuzzy sets and systems: Theory and application. United States of America: Academic Press, 57-65.

Evans, R. H. (1980). Choice criteria revisited. Journal of Marketing, 44 (1), 55-56.

Guo, Z., Qi, M., and Zhao, X. (2010). A new approach based on intuitionistic fuzzy set for selection of suppliers, Proc. of 6th International Conference on Natural Computation (ICNC 2010), 3715-3718.

Guo C., Li X. (2014). A multi-echelon inventory system with supplier selection and order allocation under stochastic demand. International Journal of Production Economics, 151, $37-47$. 
Hand, D., Mannila H. et.al. (2001). Principles of data mining, USA: Massachusetts Instittute of Technology.

Ho, W., Xiaowei X., and Dey, P. K. (2010). Multi-criteria decision making approaches for supplier evaluation and selection: A literature review. European Journal of Operational Research, 202(1),19-24.

Kaur, P. (2014a). An Intuitionistic Fuzzy Multi-Objective Vendor Selection Problem. Applied Mathematical Sciences, 8(149), 7443-7452.

Kaur, P. (2014b). Selection of Vendor Based on Intuitionistic Fuzzy Analytical Hierarchy Process, Advances in Operations Research, ss-10.

Kaur, P. and Pal. M. (2015). Selection of Vendor Based on Intuitionistic Fuzzy Linguistic Hedge. Proc. of 6th International IFS Conference, Mersin, Turkey, 69-75.

Klir, G., Yuan, B. (1993). Fuzzy sets and fuzzy logic: theory and its applications. New York: Jersey Prentice Hall, 50-11.

Liao, C. N. (2010). Supplier selection project using an integrated Delphi, AHP and Taguchi loss function. ProbStat Forum, 03, 118-134.

Liu, H.W., Wang, G. J. (2007). Multi-criteria decision-making methods based onintuitionistic fuzzy sets. European Journal of Operational Research 179, 220-233.

Liu, A., Xiao. Y., Lu, H., BingTsai, S. and Song., W. (2019). A fuzzy three-stage multi-attribute decision-making approach based on customer needs for sustainable supplier selection. Journal of Cleaner Production, 239(1), 118043.

MacQueen, J.B., (1967). Some Methods for Classification and Analysis of Multivariate Observations. Proc. Symp. Math. Statist. and Probability (5th), 281-297.

Mendoza, A., Santiago, E. and RaviRavindran, A. (2008). A three phase multicriteria method to the supplier selection problem. International Journal of Industrial Engineering, 15(2), 195-210.

Nakipoğlu, N. and Bulgurcu, B. (2020). Supplier selection in a Turkish textile company by using intuitionistic fuzzy decision-making. The Journal of the Textile Institute, 112(2).

Öztürk, M. and Tüksoy, T. (2020). Tedarikçi seçimi için yeni bir aralık tip-2 hibrit bulanık kural tabanl1 AHP sistemi. Journal of the Faculty of Engineering and Architecture of Gazi University, 35(3),1519-1535.

Pedrycz, W. (1989). Fuzzy control and fuzzy systems. Taunton: Research Studies Press John Wiley \& Sons, 225 p, Chichester.

Shipley, D. D. (1985). Reseller's supplier selection criteria for different consumer products. European Journal of Marketing, 19 (7), 26-36. 
Sotirova, E., Shannon, A., Sotirov, S. and Krawczak, M. (2014). Intuitionistic fuzzy estimation of the doctoral comprehensive examination. Notes on Intuitionistic Fuzzy Sets, 20(2), 119125.

Szmidt, E. and Kacprzyk, J. (2001). Intuitionistic Fuzzy Sets in Some Medical Applications. Notes on Intuitionistic Fuzzy Sets, 7(4), 58-64.

Türkşen, I. B. (2006). An Ontological and epistemological perspective of fuzzy set theory. Elsevier B.V., 510 p.

Zadeh, L. A. (1965). Fuzzy sets. Information Control 8, 338-353.

Zadeh, L. A. (2002). From computing with numbers to cumputing with words from manipulation of measurements to manipulation to perceptions. Int. J. Appl. Math. Comput. Sci., 12(3), $307-324$.

Xie, X. L. and Beni, G.A. (1991). Validity measure for fuzzy clustering. IEEE Trans. Pattern and Machine Intelligence, 3 (8), 841-846. 